\title{
Effect of pupillary dilation on Haigis formula- calculated intraocular lens power measurement by using optical biometry
}

This article was published in the following Dove Press journal:

Clinical Ophthalmology

27 July 2016

Number of times this article has been viewed

\author{
Bharkbhum Khambhiphant' \\ Suganlaya Sasiwilasagorn ${ }^{2}$ \\ Nattida Chatbunchachai ${ }^{3}$ \\ Krit Pongpirul ${ }^{2,4}$ \\ 'Department of Ophthalmology, \\ King Chulalongkorn Memorial \\ Hospital, Thai Red Cross Society, \\ ${ }^{2}$ Department of Ophthalmology, \\ Faculty of Medicine, Chulalongkorn \\ University, Bangkok, ${ }^{3}$ Department \\ of Ophthalmology, Samut Prakan \\ Hospital, Samut Prakan, Thailand; \\ ${ }^{4}$ Department of International Health, \\ Johns Hopkins Bloomberg School of \\ Public Health, Baltimore, MD, USA
}

Correspondence: Bharkbhum Khambhiphant

Department of Ophthalmology,

King Chulalongkorn Memorial

Hospital, Thai Red Cross Society,

Bangkok 10330, Thailand

Tel +6689811 I573

Fax +6622528290

Email bharkbhum@gmail.com
Purpose: The purpose of this study was to evaluate the effect of pupillary dilation on the Haigis formula-calculated intraocular lens (IOL) power and ocular biometry measurements by using IOLMaster ${ }^{\circledR}$.

Methods: A prospective study was performed for biometry measurements of 373 eyes of 192 healthy subjects using the IOLMaster at the outpatient department of King Chulalongkorn Memorial Hospital from February 2013 to July 2013. The axial length (AL), anterior chamber depth (ACD), keratometry (K), and IOL power were measured before and after $1 \%$ tropicamide eye drop instillation. The Haigis formula was used in the IOL power calculation with the predicted target to emmetropia. Each parameter was compared by a paired $t$-test prior to and after pupillary dilation. Bland-Altman plots were also used to determine the agreement between each parameter.

Results: The mean age of the subjects was 53.74 \pm 14.41 years (range 18-93 years). No differences in $\operatorname{AL}(P=0.03)$, steepest $\mathrm{K}(P=0.42)$, and flattest $\mathrm{K}(P=0.41)$ were obtained from the IOLMaster after pupillary dilation. However, ACD and IOL power were significantly different postdilation $(P<0.01$ and $P<0.01$, respectively). In ACD and IOL power measurements, the concordance rates were $93.03 \%$ and $97.05 \%$ within $95 \%$ limits of agreement $(-0.48$ to $0.26 \mathrm{~mm}$ and -1.09 to $0.88 \mathrm{D}$, respectively) in the Bland-Altman plots.

Conclusion: Biometry measurements in the cycloplegic stage should be considered in the IOL formulas that use parameters other than $\mathrm{AL}$ and $\mathrm{K}$.

Keywords: Haigis formula, intraocular lens, IOLMaster, optical biometry, pupillary dilation

\section{Introduction}

A good postoperative outcome of cataract surgery requires a precise biometric measurement. Optical biometry is considered worldwide as the routine diagnostic instrument for biometry measurement of intraocular lens (IOL).$^{1-5}$

In the current practice of our hospital, patients who are scheduled for cataract surgery require multiple visits to complete preoperative evaluation and biometry measurement. This is due to the process comprising complete ophthalmological examination in dilated and nondilated conditions. Many other eye centers have established one-stop service for increased patient convenience.

Our previous study showed that pupil dilation does not have an effect on the IOL power measurement using the IOLMaster ${ }^{\circledR}$ (Carl Zeiss Meditec AG, Jena, Germany). ${ }^{6}$ However, the study was conducted based on the SRK-T formula and the anterior chamber depth (ACD) was significantly increased postdilation, which was comparable to other reports. ${ }^{6-10}$ 
However, some studies have shown that this is not always precise, especially in shorter and longer axial lengths (ALs). Eyes with shorter AL often have larger lens and normal anterior chamber. ${ }^{11}$ Thus, the SRK-T formula has some disadvantages in shorter and longer AL eyes.

A fourth-generation formula has been developed to enable a more accurate measurement for short and long ALs. One of the key distinctions between SRK-T formula and the fourth-generation formula is that the fourth generation formula uses ACD measurement to calculate the IOL power. ${ }^{11-13}$ Haigis formula, the fourth-generation formula, had shown superior refractive result in various ALs and is commercially available in the IOLMaster device. ${ }^{14}$ Studies using the Haigis formula showed equivocal results in the effect of pupillary dilation on IOL power calculation by the IOLMaster. ${ }^{8-10}$ However, these studies had smaller sample sizes and the results in shorter and longer AL eyes have not been explored.

The purpose of this study was to evaluate the effect of pupil dilation on biometry measurement and IOL power calculation using the Haigis formula. The targeted refraction was emmetropia. The study also aimed to analyze the subgroups according to AL.

\section{Methods}

The project protocol was approved by the Institutional Review Board, Faculty of Medicine, Chulalongkorn University. This study was registered to Thai Clinical Trials Registry (TCTR 20150610001). This study adhered to the tenets of the declaration of Helsinki and the written informed consent was obtained from each subject.

The subjects of this study were a part of the study of Khambhiphant et al, ${ }^{6}$ which was a cohort study that enrolled the subjects presenting at the outpatient unit, Department of Ophthalmology, King Chulalongkorn Memorial Hospital, from February 2013 to July 2013. The inclusion criteria were healthy volunteer subjects older than 18 years with or without cataract.

The exclusion criteria were subjects who had used topical or systemic medication that has the effect of pupillary dilation, subjects who had previously undergone any ocular surgery that affected IOL calculation parameters, subjects with angle closure suspected (examined under Sussman four-mirror gonioscope), subjects with lens opacity too opaque to be measured using the IOLMaster, subjects with a history of mydriatic drug allergy, subjects having contact lenses on the day of examination, and subjects in whom there was inability to perform ocular fixation and maintenance in an upright position.
All the subjects in this study had his or her biometry measured using the IOLMaster Version 5 (Carl Zeiss Meditec AG, Jena, Germany) by the same operator. The measurements of $\mathrm{AL}$; keratometry (K), both flattest (K1) and steepest (K2); and ACD were collected. The Alcon SN60WF with a manufacturer-recommended $A$ constant of 119.0 for the IOLMaster was used for the IOL power calculation. The targeted refraction was emmetropia or $\pm 0.25 \mathrm{D}$. The Haigis formula was used to calculate IOL power with and without mydriasis status.

After completion of the first measurement, the subject received $1 \%$ tropicamide eye drop (Mydriacyl ${ }^{\circledR}$; Alcon Laboratories, Inc., Fort Worth, TX, USA) every 15 minutes until full dilatation $(\geq 8 \mathrm{~mm})$. Then the second measurement was performed by NC.

For subgroup analysis, the data were separated into three subgroups according to their AL: Group 1 (short AL; $\mathrm{AL}<22.0 \mathrm{~mm}$ ), Group 2 (normal AL; $\mathrm{AL}=22.0-24.5 \mathrm{~mm}$ ), and Group 3 (long AL; AL >24.5 mm).

\section{Statistical analysis}

This study used the Stata Version 13.0 program (StataCorp LP, College Station, TX, USA) for data analysis. Bland-Altman plot was used for agreement testing of ocular biometry, with $95 \%$ limits of agreement (LoA). The study accepted a deviation of $\leq \pm 0.5 \mathrm{D}$ in the IOL power measurement. $P<0.01$ was considered as statistically significant. Paired $t$-tests were performed to compare AL, K, ACD, and IOL power measurements between nondilated pupil and dilated pupil.

\section{Results}

A total of 373 eyes from 192 subjects were measured: 187 right eyes and 186 left eyes. There were eleven eyes that were not analyzed. The mean age of the subjects was $53.74 \pm 14.41$ years (range 18-93 years). The demographic data of subjects are described in Table 1.

The AL and $\mathrm{K}$ measurements did not show statistically significant difference after pupillary dilation obtained by

Table I Demographic data of subjects

\begin{tabular}{ll}
\hline Characteristics & Values \\
\hline Age, years & \\
$\mathrm{N}$ & 192 \\
Max, Min & 93,18 \\
Mean \pm SD & $53.74 \pm 14.41$ \\
Sex, $\mathrm{n}(\%)$ & \\
$\quad$ Male & $43(22.4)$ \\
$\quad$ Female & $149(77.6)$ \\
Eye side, $\mathrm{n}$ & \\
$\quad$ Right eye & 187 \\
$\quad$ Left eye & 186 \\
\hline
\end{tabular}

Abbreviations: Min, minimum; Max, maximum. 
Table 2 Ocular biometry measurements predilation and postdilation

\begin{tabular}{|c|c|c|c|c|c|}
\hline \multirow[t]{2}{*}{ Parameters } & \multicolumn{2}{|l|}{ Mean \pm SD } & \multirow{2}{*}{$\begin{array}{l}\text { Mean } \\
\text { difference }\end{array}$} & \multirow[t]{2}{*}{$95 \% \mathrm{Cl}$} & \multirow[t]{2}{*}{$P$-value } \\
\hline & Predilation & Postdilation & & & \\
\hline $\mathrm{KI}$, flattest $\mathrm{K}(\mathrm{D})$ & $44.04 \pm I .54$ & $44.03 \pm I .54$ & 0.015 & $-0.021,0.05 I$ & 0.408 \\
\hline K2, steepest K (D) & $45.02 \pm 1.6$ & $44.97 \pm 1.95$ & 0.050 & $-0.073,0.173$ & 0.422 \\
\hline $\mathrm{AL}(\mathrm{mm})$ & $23.39 \pm 1.13$ & $23.37 \pm 1.14$ & 0.013 & $0.002,0.025$ & 0.025 \\
\hline $\mathrm{ACD}(\mathrm{mm})$ & $3.16 \pm 0.38$ & $3.27 \pm 0.37$ & -0.113 & $-0.132,-0.094$ & $<0.0 \mathrm{I}$ \\
\hline IOL power (D) & $20.62 \pm 3.17$ & $20.73 \pm 3.19$ & -0.103 & $-0.155,-0.052$ & 0.0001 \\
\hline
\end{tabular}

Abbreviations: $\mathrm{K}$, keratometry; $\mathrm{AL}$, axial length; $\mathrm{ACD}$, anterior chamber depth; $\mathrm{IOL}$, intraocular lens.

the IOLMaster (AL, $0.013 \pm 0.114 \mathrm{~mm} ; P=0.02$, flattest $\mathrm{K}$, $0.015 \pm 0.349 \mathrm{D} ; P=0.41$, and steepest $\mathrm{K}, 0.05 \pm 1.205 \mathrm{D}$; $P=0.42$ ). However, ACD had significant increase after pupil dilation $(-0.11 \pm 0.188 ; P<0.01)$. Also, IOL power had significant difference $(-0.10 \pm 0.503 \mathrm{D} ; P<0.01)$ as shown in Table 2.

The correlations in ACD and IOL power change after pupillary dilation were $93.03 \%$ and $97.05 \%$ within $95 \%$ LoA ( -0.48 to $0.26 \mathrm{~mm}$ and -1.09 to $0.88 \mathrm{D}$, respectively) in the Bland-Altman plots as shown in Figures 1 and 2.

In subgroup analysis according to AL, Group 1 short axial length ( $\mathrm{AL}<22 \mathrm{~mm}$ ), Group 2 normal AL (AL 22-24.5 mm), Group 3 long AL ( $\mathrm{AL}>24.5)$, there were numbers of eyes $29,298,46$, respectively. No significant change in K (both flattest and steepest) and AL was observed in all subgroups as shown in Tables 3-5.

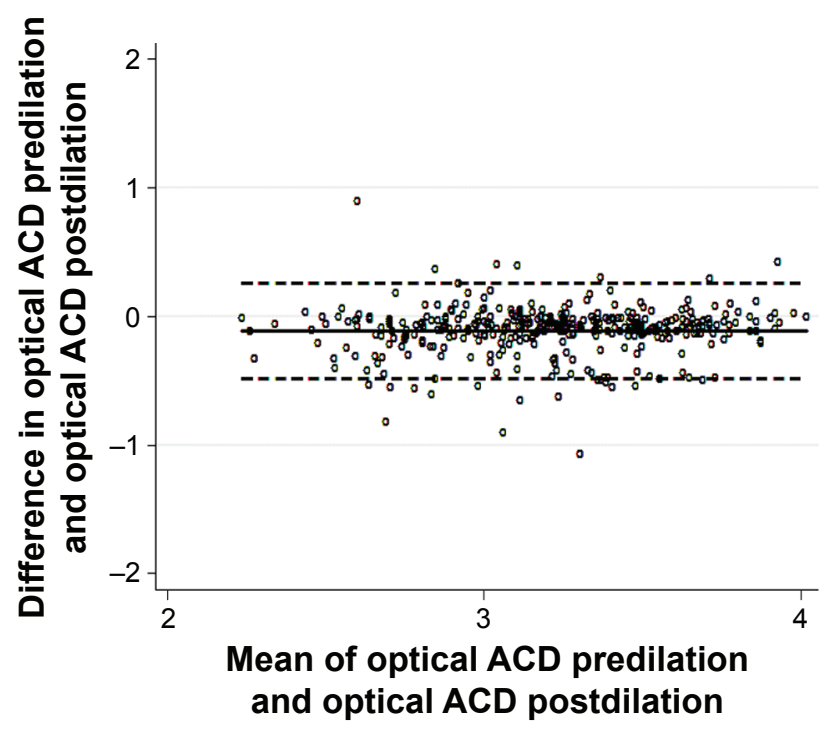

- Observed average agreement
.$- .95 \%$ LoA

Figure I Bland-Altman analysis of differences of the anterior chamber depth (ACD) before and after pupillary dilatation and mean of optical ACD predilation and Optical ACD postdilation.

Notes: The differences in the ACD before and after pupillary dilation are plotted against the mean differences. The dotted line represents the $95 \%$ LoA.

Abbreviations: ACD, anterior chamber depth; LoA, limits of agreement.
There was a significant increase in ACD after pupillary dilation in all ALs $(P<0.01)$, as shown in Table 6. Nevertheless, IOL power measurement on the Haigis formula after dilation had no significant change in short and long length group ( $P=0.11$ and $P=1.0$, respectively), as shown in Table 7 .

\section{Discussion}

Our study aimed to demonstrate the effect of the cycloplegic condition toward the parameters AL, both steepest and flattest $\mathrm{K}$ and $\mathrm{ACD}$ (the distance from corneal epithelium to the anterior surface of lens capsule), and the IOL power derived from the Haigis formula.

Drexler et $\mathrm{a}^{15}$ found the elongation of axial eye length in their subjects during accommodation by measuring with partial coherence interferometry. Mean accommodationinduced eye elongations of $12.7 \mu \mathrm{m}$ (range 8.6-19.2 $\mu \mathrm{m}$ ) in

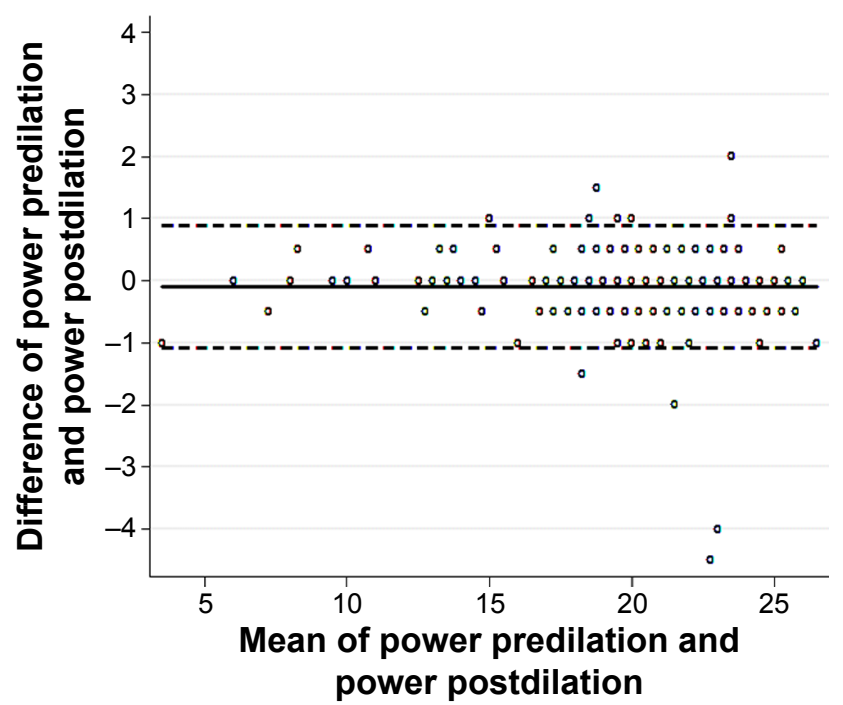

Figure 2 Bland-Altman analysis of differences of the Haigis calculated IOL power (ALCON SN60WF) before and after pupillary dilatation and mean of IOL power predilation and IOL power postdilation.

Notes: The differences in the Haigis formula-calculated IOL power (Alcon SN60WF) before and after pupillary dilation are plotted against the mean differences. The dotted line represents the 95\% LoA.

Abbreviations: IOL, intraocular lens; LoA, limits of agreement. 
Table 3 Ocular biometry measurements of short AL prepupil dilation and postpupil dilation

\begin{tabular}{|c|c|c|c|c|c|}
\hline \multirow[t]{2}{*}{ Parameters } & \multicolumn{2}{|l|}{ Mean \pm SD } & \multirow{2}{*}{$\begin{array}{l}\text { Mean } \\
\text { difference }\end{array}$} & \multirow[t]{2}{*}{$95 \% \mathrm{Cl}$} & \multirow[t]{2}{*}{$P$-value } \\
\hline & Predilation & Postdilation & & & \\
\hline KI flattest $K(D)$ & $46.11 \pm 1.10$ & $46.07 \pm 1.17$ & 0.038 & $-0.045,0.122$ & 0.355 \\
\hline K2 steepest K (D) & $46.97 \pm 1.21$ & $46.95 \pm 1.29$ & 0.022 & $-0.112,0.158$ & 0.732 \\
\hline $\mathrm{AL}(\mathrm{mm})$ & $21.72 \pm 0.25$ & $21.72 \pm 0.25$ & 0.001 & $-0.008,0.010$ & 0.823 \\
\hline $\mathrm{ACD}(\mathrm{mm})$ & $2.95 \pm 0.34$ & $3.04 \pm 0.31$ & -0.082 & $-0.117,-0.048$ & $<0.01$ \\
\hline IOL power (D) & $23.84 \pm 1.48$ & $23.98 \pm 1.62$ & -0.138 & $-0.313,0.037$ & 0.118 \\
\hline
\end{tabular}

Abbreviations: $A L$, axial length; $K$, keratometry; $A C D$, anterior chamber depth; IOL, intraocular lens.

Table 4 Ocular biometry measurements of normal AL predilation and postdilation

\begin{tabular}{|c|c|c|c|c|c|}
\hline \multirow[t]{2}{*}{ Parameters } & \multicolumn{2}{|l|}{ Mean \pm SD } & \multirow{2}{*}{$\begin{array}{l}\text { Mean } \\
\text { difference }\end{array}$} & \multirow[t]{2}{*}{$95 \% \mathrm{Cl}$} & \multirow[t]{2}{*}{$P$-value } \\
\hline & Predilation & Postdilation & & & \\
\hline KI flattest $K(D)$ & $43.97 \pm 1.38$ & $43.96 \pm 1.38$ & 0.017 & $-0.026,0.059$ & 0.435 \\
\hline K2 steepest K (D) & $44.94 \pm 1.47$ & $44.88 \pm 1.92$ & 0.062 & $-0.091,0.215$ & 0.425 \\
\hline $\mathrm{AL}(\mathrm{mm})$ & $23.21 \pm 0.59$ & $23.19 \pm 0.60$ & 0.017 & $0.002,0.031$ & 0.024 \\
\hline $\mathrm{ACD}(\mathrm{mm})$ & $3.13 \pm 0.37$ & $3.24 \pm 0.36$ & -0.119 & $-0.141,-0.098$ & $<0.01$ \\
\hline IOL power (D) & $21.25 \pm 1.69$ & $21.36 \pm 1.68$ & -0.116 & $-0.175,-0.056$ & 0.0002 \\
\hline
\end{tabular}

Abbreviations: AL, axial length; K, keratometry; ACD, anterior chamber depth; IOL, intraocular lens.

Table 5 Ocular biometry measurements of long AL prepupillary dilation and postpupillary dilation

\begin{tabular}{|c|c|c|c|c|c|}
\hline \multirow[t]{2}{*}{ Parameters } & \multicolumn{2}{|l|}{ Mean \pm SD } & \multirow{2}{*}{$\begin{array}{l}\text { Mean } \\
\text { difference }\end{array}$} & \multirow[t]{2}{*}{$95 \% \mathrm{Cl}$} & \multirow[t]{2}{*}{$P$-value } \\
\hline & Predilation & Postdilation & & & \\
\hline KI flattest $K(D)$ & $43.17 \pm 1.66$ & $43.18 \pm 1.69$ & -0.012 & $-0.086,0.062$ & 0.747 \\
\hline K2 steepest $K(D)$ & $44.29 \pm 1.76$ & $44.30 \pm 1.80$ & -0.009 & $-0.076,0.058$ & 0.789 \\
\hline $\mathrm{AL}(\mathrm{mm})$ & $25.60 \pm I .1 I$ & $25.60 \pm 1.11$ & -0.001 & $-0.007,0.006$ & 0.832 \\
\hline $\mathrm{ACD}(\mathrm{mm})$ & $3.48 \pm 0.28$ & $3.57 \pm 0.26$ & -0.092 & $-0.161,-0.023$ & 0.0098 \\
\hline IOL power (D) & $14.57 \pm 3.97$ & $14.57 \pm 3.96$ & 0 & $-0.117,0.117$ & 1.0 \\
\hline
\end{tabular}

Abbreviations: AL, axial length; K, keratometry; ACD, anterior chamber depth; IOL, intraocular lens.

Table 6 Subgroup analysis of ACD

\begin{tabular}{llllll}
\hline AL $(\mathbf{m m})$ & $\mathbf{n}(\%)$ & \multicolumn{2}{l}{ ACD $(\mathbf{m m})$, mean \pm SD } & 95\% CI & \multicolumn{1}{c}{-value } \\
\cline { 2 - 5 } & & Predilation & Postdilation & & \\
\hline AL $<22$ & $29(7.77)$ & $2.95 \pm 0.34$ & $3.04 \pm 0.31$ & $-0.117,-0.048$ & $<0.01$ \\
AL 22.0-24.5 & $298(79.89)$ & $3.13 \pm 0.37$ & $3.24 \pm 0.36$ & $-0.141,-0.098$ & $<0.01$ \\
AL $>24.5$ & $46(12.33)$ & $3.48 \pm 0.28$ & $3.57 \pm 0.26$ & $-0.161,-0.023$ & 0.0098 \\
\hline
\end{tabular}

Abbreviations: $A C D$, anterior chamber depth; $A L$, axial length.

Table 7 Subgroup analysis of IOL power calculation

\begin{tabular}{llllll}
\hline AL $(\mathbf{m m})$ & $\mathbf{n}(\%)$ & \multicolumn{2}{l}{ IOL power $(\mathbf{D})$, mean \pm SD } & 95\% Cl & P-value \\
\cline { 2 - 5 } & & Predilation & Postdilation & & \\
\hline AL $<22$ & $29(7.77)$ & $23.84 \pm 1.48$ & $23.98 \pm 1.62$ & $-0.313,0.037$ & 0.118 \\
AL 22-24.5 & $298(79.89)$ & $21.25 \pm 1.69$ & $21.36 \pm 1.68$ & $-0.175,-0.056$ & $<0.01$ \\
AL $>24.5$ & $46(12.33)$ & $14.57 \pm 3.97$ & $14.57 \pm 3.96$ & $-0.117,0.117$ & 1.0 \\
\hline
\end{tabular}

Abbreviations: IOL, intraocular lens; AL, axial length. 
emmetropia and $5.2 \mu \mathrm{m}$ (range 2.1-9.5 $\mu \mathrm{m}$ ) in myopia were obtained. Sheng et al ${ }^{16}$ found that cycloplegia had no significant effect on AL measurements but produced a significant increase in ACD measured using the IOLMaster. Cheung et $\mathrm{al}^{17}$ found that the effect of cycloplegia on AL measurement using the IOLMaster was insignificant in children aged from 7 years to 15 years; meanwhile, ACD measurement was significantly affected by cycloplegia. Huang et al found that the cycloplegic stage had no significant effect on AL or corneal curvature that was measured from another machine named Lenstar (Haag-Streit AG, Koeniz, Switzerland). However, ACD and white-to-white diameter significantly increased postcycloplegia (Lenstar, $0.09 \pm 0.06 \mathrm{~mm}$ and $0.10 \pm 0.17 \mathrm{~mm}$, respectively; IOLMaster, $0.06 \pm 0.07 \mathrm{~mm}$ and $0.43 \pm 0.35 \mathrm{~mm}$, respectively; $P<0.001){ }^{8}$

In our first project, we found significant difference in ACD after pupillary dilation, whereas the AL, both steepest and flattest $\mathrm{K}$, and SRK-T-calculated IOL power did not change significantly. ${ }^{6}$ The differences between ACD values and IOL powers were nominal in the vast majority of cases. This was similar to the study of Adler et al. ${ }^{18}$

Heatley et $\mathrm{al}^{7}$ showed a statistically significant change in $\mathrm{K} 2$ and average $\mathrm{K}$ values, but there was no significant change in AL and IOL power in the cycloplegic stage using the IOLMaster. Rodriguez-Raton et al also found that pupil dilation with tropicamide and phenylephrine eye drop produced a significant increase in ACD when measured by the IOLMaster. The results of IOL power prediction from the Haigis formula were changed. These changes resulted in a different IOL power prediction according to the Haigis formula, which calculated the effective lens position taking into account the ACD.${ }^{10}$ Arriola-Villalobos et $\mathrm{al}^{19}$ found an insignificant IOL power change in the Holladay II formula, but they had a small number of eyes and performed their analysis using Lenstar.

In our study, the ACD had significantly increased after pupil dilation $(-0.11 \pm 0.188)(P<0.01)$. The IOL power also showed a significant difference $(-0.10 \pm 0.503 \mathrm{D} ; P<0.01)$. We also found from the Bland-Altman plots that changes in ACD and IOL power distribution were $6.97 \%$ and $2.95 \%$ out of $95 \%$ LoA ( -0.48 to $0.26 \mathrm{~mm}$ and -1.09 to $0.88 \mathrm{D}$, respectively). In addition, in this study, we set up the acceptance of IOL power $\leq \pm 0.50 \mathrm{D}$. This made the surgeon aware of the IOL selection in high-expectation patients who need the best results. We need to compare the estimated refraction of the target IOL power with the other formulas before choosing the final power.

The limitations of our study are the limited numbers of subjects. It was shown in the subgroup analysis that the small samples of short AL $(P=0.11)$ and long $\mathrm{AL}(P=1.0)$ possibly affected the significant difference results of IOL power between predilation and postdilation. The ocular surface status of each subject, instilled with different dosages of $1 \%$ tropicamide before measuring with the IOLMaster, should be considered with caution.

However, the biometry measurements in the cycloplegic stage should be considered in the IOL formulas that use parameters other than AL and K. Our study accepted the deviation of $\leq \pm 0.5 \mathrm{D}$ in IOL power; therefore, factors such as the corneal astigmatism of each subject should be taken into account before the IOL selection. The future of cataract surgery is still challenging for all cataract surgeons, especially for subjects with different eye conditions such as short and long ALs, high corneal astigmatism, postcorneal refractive surgery, and the new presbyopic IOL.

\section{Acknowledgment}

This article was presented on Thursday, July 9, 2015, at the 35th Annual Scientific Meeting of the Royal College of Ophthalmologists of Thailand, Bangkok Convention Center, Centara Grand at CentralWorld, Bangkok, Thailand.

\section{Disclosure}

All authors certify that they have no affiliations with or involvement in any organization or entity with any financial interest (such as honoraria; educational grants; participation in speakers' bureaus; membership, employment, consultancies, or stock ownership, or other equity interest and expert testimony or patent-licensing arrangements) or nonfinancial interest (such as personal or professional relationships, affiliations, knowledge, or beliefs) in the subject matter or materials discussed in this manuscript. The authors report no other conflicts of interest in this work.

\section{References}

1. Lee AC, Qazi MA, Pepose JS. Biometry and intraocular lens power calculation. Curr Opin Ophthalmol. 2008;19:13-17.

2. Kielhorn I, Rajan MS, Tesha PM, Subryan VR, Bell JA. Clinical assessment of the Zeiss IOLMaster. J Cataract Refract Surg. 2003;29: 518-522.

3. Németh J, Fekete O, Pesztenlehrer N. Optical and ultrasound measurement of axial length and anterior chamber depth for intraocular lens power calculation. J Cataract Refract Surg. 2003;29:85-88.

4. Haigis W, Lege B, Miller N, Schneider B. Comparison of immersion ultrasound biometry and partial coherence interferometry for the intraocular lens calculation according to Haigis. Graefes Arch Clin Exp Ophthalmol. 2000;238:765-773.

5. Chen YA, Hirnschall N, Findl O. Evaluation of 2 new optical biometry devices and comparison with current gold standard biometer. J Cataract Refrac Surg. 2011;37:513-517. 
6. Khambhiphant B, Chatbunchachai N, Pongpirul K. The effect of pupillary dilatation on IOL power measurements by using the IOLMaster. Int Ophthalmol. 2015;35:853-859.

7. Heatley CJ, Whitefield LA, Hugkulstone CE. Effect of pupil dilation on the accuracy of the IOLMaster. J Cataract Refract Surg. 2002;28: 1993-1996.

8. Huang J, McAlinden C, Su B, et al. The effect of cycloplegia on the lenstar and the IOLMaster biometry. Optom Vis Sci. 2012;89:1691-1696.

9. Bakbak B, Koktekir BE, Gedik S, Guzel H. The effect of pupil dilation on biometric parameters of the Lenstar 900. Cornea. 2013; 32(4):e21-e24.

10. Rodriguez-Raton A, Jimenez-Alvarez M, Arteche-Limousin L, Mediavilla-Peña E, Larrucea-Martinez I. Effect of pupil dilation on biometry measurements with partial coherence interferometry and its effect on IOL power formula calculation. Eur J Ophthalmol. 2015;25(4): 309-314.

11. Hill WE. The Haigis formula for IOL power calculation. Geriatric Ophthalmol. 2002;1(1):8.

12. Olsen T. Calculation of intraocular lens power: a review. Acta Ophthalmol Scand. 2007;85:472-485.

13. Eom Y, Kang SY, Song JS, Kim YY, Kim HM. Comparison of Hoffer $\mathrm{Q}$ and Haigis formulae for intraocular lens power calculation according to the anterior chamber depth in short eyes. Am J Ophthalmol. 2014; 157:818-824.
14. Wang JK, Chang SW. Optical biometry intraocular lens power Calculation using different formulas in patients with different axial lengths. Int J Ophthalmol. 2013;6:150-154.

15. Drexler W, Findl O, Schmetterer L, Hitzenberger CK, Fercher AF. Eye elongation during accommodation in humans: differences between emmetropes and myopes. Invest Ophthalmol Vis Sci. 1998;39(11): 2140-2147.

16. Sheng H, Bottjer CA, Bullimore MA. Cycloplegia had no significant effect on IOLMaster axial length measurements. Optom Vis Sci. 2004; 81(1):27-34.

17. Cheung SW, Chan R, Cheng RC, Cho P. Effect of cycloplegia on axial length and anterior chamber depth measurements in children. Clin Exp Optom. 2009;92(6):476-481.

18. Adler G, Shahar J, Kesner R, et al. Effect of pupil size on biometry measurements using the IOLMaster. Am J Ophthalmol. 2015;159(5): 940-944.

19. Arriola-Villalobos P, Díaz-Valle D, Garzòn N, et al. Effect of pharmacologic pupil dilation on OLCR optical biometry measurements for IOL predictions. Eur J Ophthalmol. 2014;24(1):53-57.
Clinical Ophthalmology

\section{Publish your work in this journal}

Clinical Ophthalmology is an international, peer-reviewed journal covering all subspecialties within ophthalmology. Key topics include: Optometry; Visual science; Pharmacology and drug therapy in eye diseases; Basic Sciences; Primary and Secondary eye care; Patient Safety and Quality of Care Improvements. This journal is indexed on Submit your manuscript here: http://www.dovepress.com/clinical-ophthalmology-journal

\section{Dovepress}

PubMed Central and CAS, and is the official journal of The Society of Clinical Ophthalmology (SCO). The manuscript management system is completely online and includes a very quick and fair peer-review system, which is all easy to use. Visit http://www.dovepress.com/ testimonials.php to read real quotes from published authors. 